\title{
Real-time methylation-specific PCR for the evaluation of methylation status of MGMT gene in glioblastoma
}

\author{
Masaki Yoshioka ${ }^{1,2}$, Tomoo Matsutani ${ }^{1}$, Ayaka Hara $^{1}$, Seiichiro Hirono ${ }^{1}$, Takaki \\ Hiwasa $^{2}$, Masaki Takiguchi ${ }^{2}$ and Yasuo Iwadate $^{1}$ \\ ${ }^{1}$ Department of Neurological Surgery, Chiba University Graduate School of Medicine, Chiba, Japan \\ ${ }^{2}$ Department of Biochemistry and Genetics, Chiba University Graduate School of Medicine, Chiba, Japan \\ Correspondence to: Yasuo Iwadate, email: iwadatey@faculty.chiba-u.jp \\ Keywords: glioma; MGMT; methylation; real-time PCR; MSP
}

Received: February 07, $2018 \quad$ Accepted: May 09, $2018 \quad$ Published: June 12, 2018

Copyright: Yoshioka et al. This is an open-access article distributed under the terms of the Creative Commons Attribution License 3.0 (CC BY 3.0), which permits unrestricted use, distribution, and reproduction in any medium, provided the original author and source are credited.

\section{ABSTRACT}

The methylation status of the 06-methylguanine-DNA methyltransferase (MGMT) gene is a strong predictor for the efficacy of temozolomide chemotherapy and survival periods. However, the correlation between the extent of methylation and the difference in survival times has not been fully clarified. Simple and quantitative evaluations of the methylation status in the promotor region of the MGMT gene are expected to be worldwide standardized diagnostics. We applied real-time semiquantitative methylation-specific polymerase chain reaction (SQ-MSP) of the MGMT gene promoter region to 84 glioblastoma patients. The SQ-MSP result showed that the $\Delta \mathrm{Ct}$ value, which represents the difference between uCt and $\mathrm{mCt}$ (uCt value - mCt value), is inversely correlated with overall survival. With adequate cutoff setting, this assay showed that those patients suffering from a tumor with low $\Delta \mathrm{Ct}$ (methylated) survived significantly longer than those having tumors with high $\Delta \mathrm{Ct}$ (un-methylated). The most significant difference was observed when the cutoff was set at a $\Delta$ Ct of 2 . Using this cutoff point, the result of MGMT immunohistochemical analysis was also significantly correlated with the methylation status examined with real-time SQ-MSP. These results collectively show that MGMT promoter methylation status actually affects patients' survival and protein expression depending on its methylation level, and the extent of methylated CPGs would be better assessed with real-time SQMSP than with the standard gel-based MSP. This method is cost- and labor-saving compared with pyrosequencing, and significantly contributes to the accurate and objective prediction of patient survival.

\section{INTRODUCTION}

Glioblastoma is one of the most malignant cancers of the central nervous system. Standard treatment includes radiotherapy and temozolomide chemotherapy after surgery. Temozolomide is an alkylating agent which causes DNA damage by delivering a methyl group to purine bases of DNA (O6-guanine; N7-guanine and N3-adenine) and induces apoptosis [1]. However, O6methylguanine-DNA methyltransferase (MGMT), which is a DNA repair protein, reverses alkylation at the O6 position of guanine, thus decreasing the cytotoxic effects of alkylating drugs such as temozolomide. Silencing the MGMT gene by promoter methylation results in decreased MGMT expression and improves the effects of temozolomide [2-3].

Recent studies have shown that MGMT gene promoter methylation status, either methylated or unmethylated, is related to patient survival; patients with high levels of MGMT gene promoter methylation status are expected to survive longer [4-5]. It is important to accurately evaluate the methylation status of the MGMT 
gene promoter in clinical decision making for treatment selection and in the development of novel therapies including MGMT silencing by tumor-targeted siRNA delivery [6-8]. There are several methods that can be used to analyze MGMT promoter methylation, including pyrosequencing (PSQ), methylation-specific polymerase chain reaction (MSP), methylation-specific multiplex ligation-dependent probe amplification (MS-MLPA), and Infinium Methylation BeadChip technology [9-14]. Many researchers consider PSQ to be the best method because it can be used to analyze the methylated ratio of each target $\mathrm{CpG}$ site separately [10-12]. However, it is difficult to interpret PSQ data into clinically-relevant information correlating with MGMT protein expression or patient survival. Furthermore, this method is cost- and labor-intensive, with a necessity for initial investment in the novel sequencer, which prevents this assay from being a world-wide standard essential for the clinical routine and clinical trials. An easier and more quantitative method for analyzing the MGMT promoter methylation status is needed in order to obtain clinically-relevant information in daily medical practice.

MSP is a cost- and labor-saving method compared with PSQ and can be performed with simple equipment. However, the prevalent MSP is subjective in evaluation because of a lack in quantitative data formation. To facilitate objective evaluation of MSP data, real-time MSP using SYBR-Green technology offers an easy way to semi-quantitatively express the methylation status without requiring the laborious gel electrophoresis [15-17]. In this study, we showed that the real-time semi-quantitative MSP (SQ-MSP) is an effective method for evaluating the methylation status of the MGMT gene promoter for the accurate prediction of patient survival.

\section{RESULTS}

\section{Real-time MSP}

The most appropriate way to read data is to look at the dissociation curve first and check whether there is a methylation primer specific peak at $81^{\circ} \mathrm{C}$. When there is such a at $81^{\circ} \mathrm{C}$ in the dissociation curve, there are methylated tumor cells in the sample. If not, there are no methylated tumor cells in the sample, and those having no peak at $81^{\circ} \mathrm{C}$ in dissociation curve were considered to be unmethylated tumors. In the amplification curve, we can see how much DNA is being amplified. The number of PCR cycles at which the amplification curve exceeds a certain threshold-fluorescence was $0.1 \mathrm{dRn}$ in this study - is defined as the $\mathrm{Ct}$ value. The threshold should be determined at the value where the slope of the amplification curve is not an exponential amplification but a stable amplification. Thus, $\mathrm{mCt}$ means that the amplification curve of methylated MGMT primer at the PCR cycle and uCt corresponds to unmethylated MGMT.
In order to quantify the methylation status, we evaluated the $\Delta \mathrm{Ct}$ value, which represents the difference between $\mathrm{uCt}$ and $\mathrm{mCt}$ (uCt value $-\mathrm{mCt}$ value). The $\Delta \mathrm{Ct}$ values of the tumors having no peak at $81^{\circ} \mathrm{C}$ in dissociation curve were between 4 and 10 . In contrast, the tumors with a large peak at $81^{\circ} \mathrm{C}$ have a relatively small $\Delta \mathrm{Ct}$, mainly around 0 . These tumors were considered to be in the methylated group. A scatter diagram was obtained, showing the relationship between the $\Delta \mathrm{Ct}$ value and the survival period in months (Figure 1). The scatter diagram shows that the survival time of the patients with unmethylated tumors tends to be short, whereas the samples with a small $\Delta \mathrm{Ct}$ value contain many longterm survivors. There was a negative correlation between the $\Delta \mathrm{Ct}$ value and patient survival time $(\mathrm{R}=0.361$, $p=0.0010)$.

\section{$\Delta C t$ cutoff for the most precise survival prediction}

In order to clinically apply this research, we would like to classify those samples having a peak at $81^{\circ} \mathrm{C}$ into either the methylated group or the unmethylated group by $\Delta \mathrm{Ct}$ value. The smaller the $\Delta \mathrm{Ct}$ value is, the greater the proportion of methylated cells and the greater the extent of the methylated region in each cell. Therefore, we set five cutoffs to distinguish between the methylated and unmethylated groups, and compared the survival period between the two groups in each cutoff (Figure 2). When the $\Delta$ Ct cutoff value was set at $0,2,4,6$, and 8 , all of the comparisons except with a cutoff of 8 yielded statistically significant differences. The smallest $p$-value was obtained at the cutoff off 2 .

\section{Comparison of $\Delta \mathrm{Ct}$ and gel electrophoresis of MSP products}

To extend real-time MSP to the worldwide -routine clinical practice, it is important to visualize the band intensity at each $\Delta \mathrm{Ct}$ (Figure 3). Although the $\Delta \mathrm{Ct}$ values varied from 1 to 8 , there were distinct methylated bands on the gels. When the $\Delta \mathrm{Ct}$ was approximately over 10 or in the sample having no peak at $81^{\circ} \mathrm{C}$, no apparent band was visualized in the gels. This indicates that a wide range in the proportion of methylated cells or in the extent of the methylated regions in each cell results in a band formation in the methylated lane. Actually, the functional threshold of MGMT promoter methylation may be within in the range of $\Delta \mathrm{Ct}$ yielding the methylated band on the gel.

\section{Correlation of real-time MSP and MGMT protein expression}

We ultimately examined the correlation of the $\Delta \mathrm{Ct}$ from real-time MSP results and the MGMT protein 
expression evaluated by immunohistochemistry. Although the valid evaluation of immunohistochemical analyses is not easy, judgement of negative results usually does not give significant discordance. We regarded a negative immunohistochemical result as a surrogate target, and examined the correlation with real-time MSP results; unmethylated results linked with protein-positive was judged as positive-predictive values (PPV) and methylated results linked with protein-negative was judged as negative-predictive values (NPV). When the

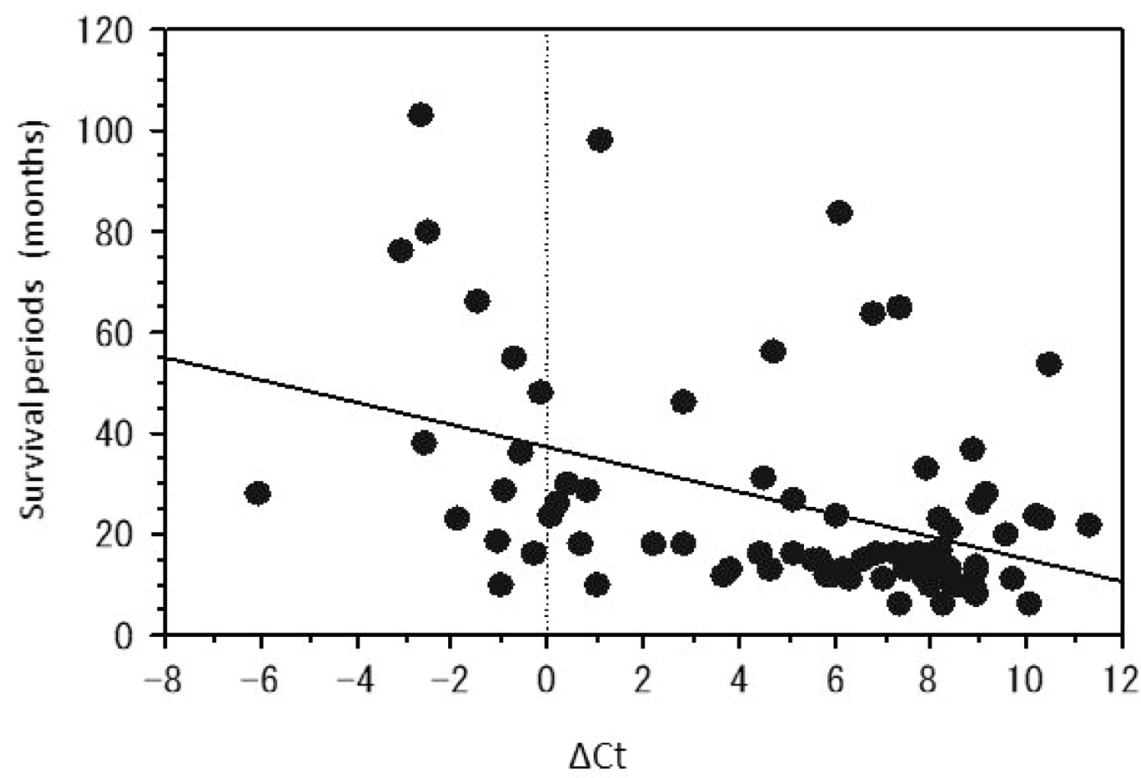

Figure 1: The scatter diagrams of the relationship between the $\Delta \mathrm{Ct}$ values and the survival periods of the patients with glioblastoma having the peak at $81^{\circ} \mathrm{C}$. The survival period is inversely proportional to the $\Delta \mathrm{Ct}$ obtained by the real-time semiquantitative methylation specific PCR (SQ-PCR).

A Cutoff : $\Delta \mathrm{Ct}=0$

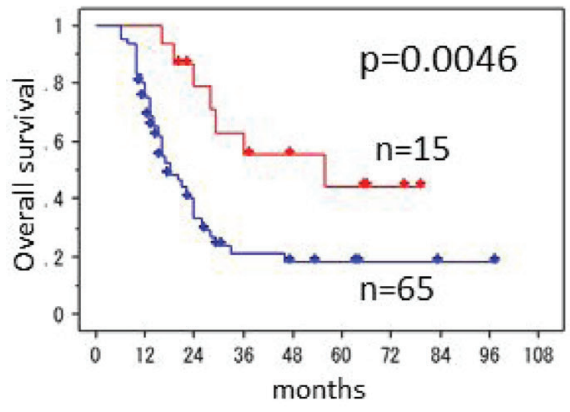

D

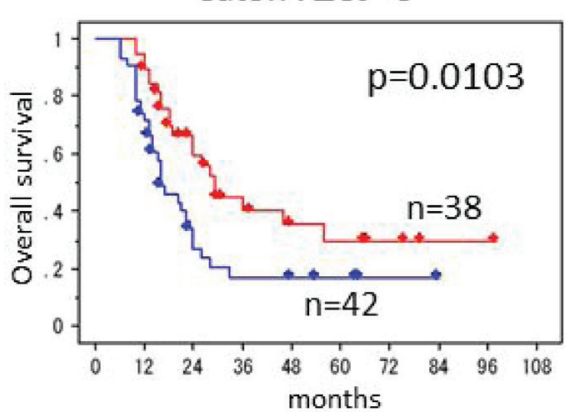

B

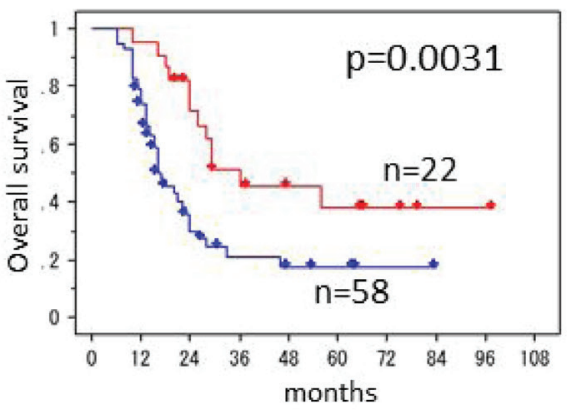

E

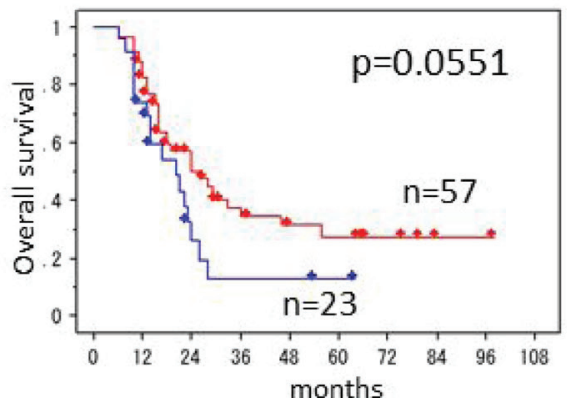

C Cutoff : $\Delta \mathrm{Ct}=4$
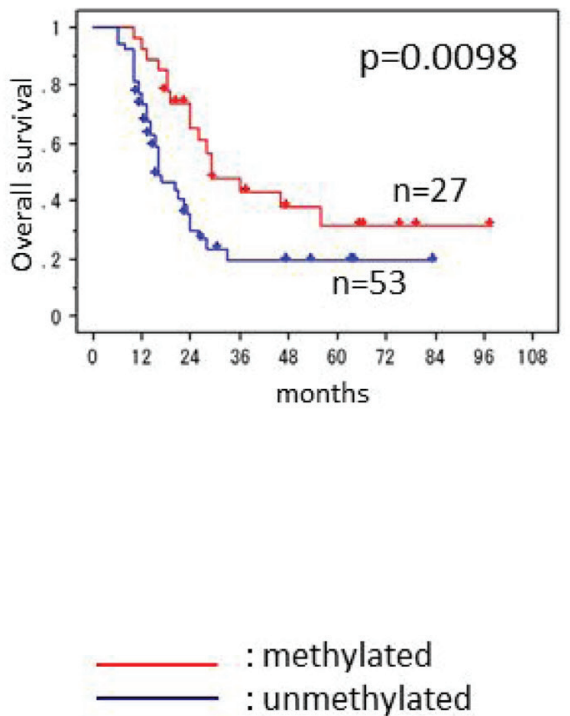

Figure 2: Kaplan-Meier survival curves of the patients with glioblastoma. Five cutoffs of $\Delta \mathrm{Ct}$ values were applied to separate methylated and unmethylated groups; (A) cutoff $\Delta \mathrm{Ct}$ of $0,(\mathbf{B})$ cutoff $\Delta \mathrm{Ct}$ of 2, (C) cutoff $\Delta \mathrm{Ct}$ of 4 , (D) cutoff $\Delta \mathrm{Ct}$ of 6 , (E) cutoff $\Delta \mathrm{Ct}$ of 8. The smallest $p$-value was obtained at the cutoff off 2. 
methylation status was determined only by the presence of a methylation primer specific peak at $81^{\circ} \mathrm{C}$ in the dissociation curve, the PPV was $93 \%$ and the NPV was $58 \%$. There was a highly significant correlation in the methylation status of the MGMT promoter region and MGMT protein expression $(p<0.00001$, Fisher exact test). However, when the judgement of the methylation status included a $\Delta \mathrm{Ct}$ with a cutoff value of 2 , the PPV was $92 \%$ and the NPV was $70 \%$. The PPV was almost the same, but the NPV was remarkably improved. When $\Delta \mathrm{Ct}$ with cutoff values of 4 and 6 were used, the PPVs were 94 and $91 \%$, and the NPVs were 53 and 47\%, respectively (Table 1). Overall, a $\Delta \mathrm{Ct}$ with a cutoff value of 2 yielded the most excellent predictive values for MGMT protein expression.

\section{DISCUSSION}

In the present study, we clearly showed that the information obtained from real-time SQ-MSP concerning MGMT promoter methylation status is highly correlated with the survival period of the GBM patients treated with the standard Stupp's protocol. The results of realtime SQ-MSP are also highly correlated with the protein expression examined by immunohistochemistry. The heterogeneous methylation patterns of respective cases were adequately evaluated by SQ-MSP, which led to its high correlation with both patient survival and MGMT protein expression.

Although some contradictory results have been reported [18, 19], the correlation of MGMT promoter methylation status with patient survival is well demonstrated. In previous studies, it has been shown by many authors that the outcome is better in patients with MGMT promoter methylation, which is usually determined by gel-based MSP in the clinical routine $[2,3,20-24]$. However, the relationship of MGMT methylation status to MGMT protein expression is controversial, with many researchers reporting that there is no significant correlation [18, 22, 23, 25]. Methylation status is usually so heterogeneous within a tumor, not in an all-or-none manner, that the way to quantitatively or semi-quantitatively assess methylation status has long been discussed [4, 5, 9-13]. The present result shows that there is a positive relationship between MGMT promoter methylation and protein expression when the methylation status is adequately examined with SQ-MSP. It is a cardinal rule of biology that promoter methylation beyond a certain amount has a definite effect on silencing gene expression.

Human MGMT promoter regions include $98 \mathrm{CpG}$ sites and only a portion of the sites are used for standard MSP or pyrosequencing [26]. The extent of MGMT promoter methylation is different among tumor cells [2729], and normal cells usually contaminate all samples, all of which affect the real-time MSP results. The minimal methylation level at the $\mathrm{CpG}$ sites that is required to suppress MGMT protein expression has not been fully elucidated. The criterion obtained by utilizing cell lines is not easily adapted into clinics because of the complexity of human GBM samples intermingled with non-neoplastic cells such as microglia and macrophages. That is because the quantitative assessment of MGMT methylation status with an appropriate threshold setting focusing on patient outcomes is quite important for reliable clinical application. The real-time SQ-MSP result is actually

A

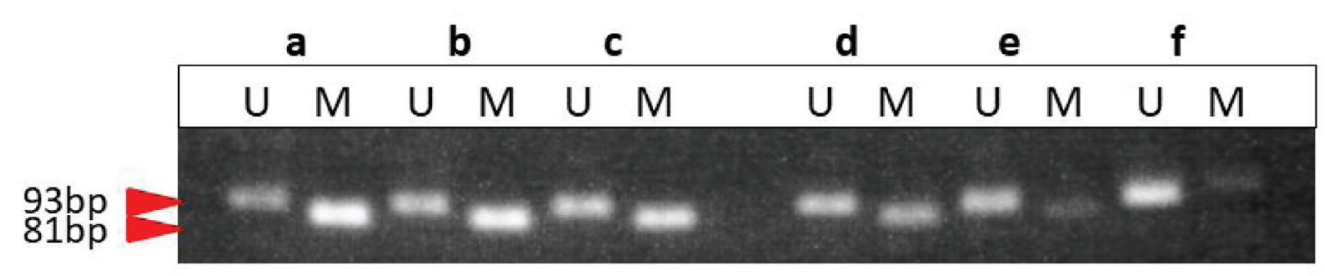

B
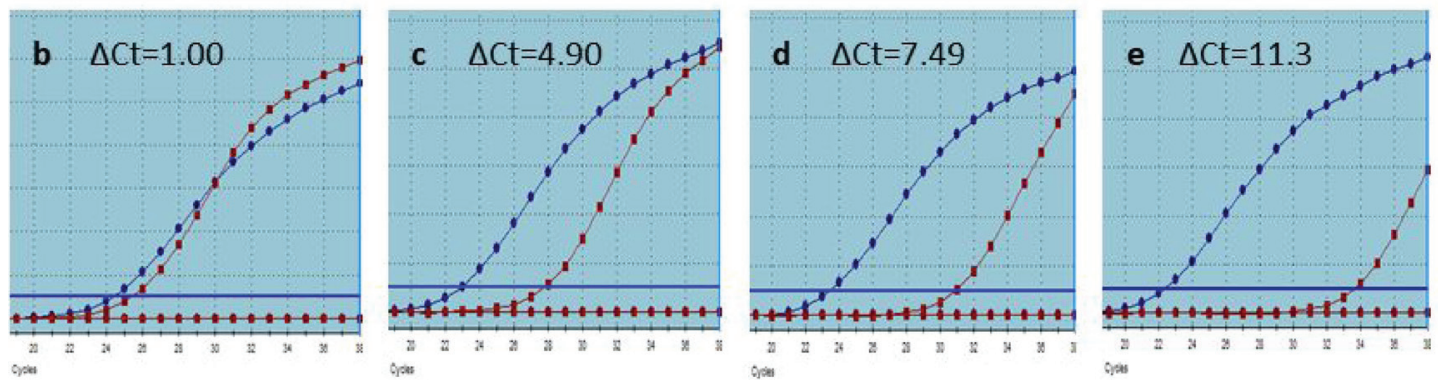

Figure 3: Correlation of the band intensity on the gel (A) and the dissociation curves at each $\Delta \mathrm{Ct}(\mathbf{B})$. Only when the $\Delta \mathrm{Ct}$ was approximately over 10 or in the sample having no peak at $81^{\circ} \mathrm{C}$, no apparent band was visualized in the gels. 
Table 1: PPV and NPV according to the cutoff value in $\Delta \mathrm{Ct}$

\begin{tabular}{lccc}
\hline $\boldsymbol{\Delta C}$ t value & PPV (\%) & NPV (\%) & $p$-value \\
\hline None & 93 & 59 & $<0.0001$ \\
2 & 92 & 71 & $<0.0001$ \\
4 & 94 & 54 & $<0.0001$ \\
6 & 100 & 53 & $<0.0001$ \\
\hline
\end{tabular}

Abbreviations: PPV: Positive predictive value

NPV: Negative predictive value

highly correlated with the MGMT immunohistochemical results as well as the patient outcomes, which can be attributed to the adequate threshold setting. Although the primers used in this study are designed to encompass the well-correlated regions with MGMT protein expression, it is not clear if these $\mathrm{CpG}$ sites best reflect the status of expression. We should consider the possibility that another combination of methylation sites would affect the MGMT activity of the tumors.

In this study, the methylation status was evaluated with the real-time SQ-MSP, introducing the $\Delta \mathrm{Ct}$ value to "relatively" quantify the MGMT promoter methylation. The result is that patient survival time is negatively correlated with $\Delta \mathrm{Ct}$. The difference in survival periods between two groups divided by $\Delta \mathrm{Ct}$ was most significant when it was set at $2(p=0.0031)$. This cutoff value also led to the most significant correlation of the methylation status with the protein expression. Since gel electrophoresis of the MSP products showed both methylated and unmethylated bands of varying degrees, quantification of the extent of methylation is important for the precise clinical application of the MSP results.

Indeed, when the $\Delta \mathrm{Ct}$ value was 2 , the rate of MGMT promoter methylation was 0.275 , which is considerably lower than that in previous reports of around 0.4 [3, 27-29]. The gel-based MSP included tumors with slightly-methylated MGMT promoter that were not sufficiently methylated to repress MGMT protein expression [30-32]. That is partly because MSP is prone to false-positive results and there were some negative reports for the predictive and prognostic values of MGMT methylation status [22]. Although regulation of MGMT protein expression is affected by many other factors, it was shown here that the promoter methylation is clearly involved in the inactivation of the MGMT gene, resulting in a clinically-significant shortage of the protein. Overall, the evaluation of MGMT promoter methylation using real-time SQ-MSP is quite useful for predicting the efficacy of temozolomide in clinical practice. However, although the $\Delta \mathrm{Ct}$ precisely represents the methylation level of the MGMT promoter, it should be noted that the value is not an absolute numerical value that quantifies the methylated $\mathrm{CpG}$ islands.

The real-time SQ-MSP examined here is costefficient and can easily be introduced into routine work without a large initial financial investment, making the evaluation of MGMT promoter methylation status more reliable than the gel-based MSP which is currently assumed to be the gold standard for MGMT methylation analysis.

\section{MATERIALS AND METHODS}

\section{Patients and tissue specimens}

Eighty-four patients with GBM were included in this study. The background characteristics are summarized in Table 2. IDH1 immunohistochemistry was positive in only three cases. All tissue samples were obtained from patients at the Chiba University Hospital under a protocol approved by the Ethics Committee of the Chiba University Graduate School of Medicine, and informed consent was obtained from the patients or their guardians. The histopathological diagnoses for all specimens were confirmed by two independent neuropathologists, according to the criteria established by the World Health Organization. The patients with GBM were homogeneously treated with 60 Gy local-field irradiation and concurrent temozolomide. The initial chemotherapy protocol was administered precisely according to Stupp's regimen. All tumor specimens investigated were obtained at the time of the first surgery for each patient. A portion of each sample was fixed in 10\% formaldehyde and embedded in paraffin, and the remainder of the sample was immediately frozen in liquid nitrogen and stored at $-80^{\circ} \mathrm{C}$ until protein extraction.

\section{DNA extraction and bisulfite conversion}

In the first step of the experiment, we extracted DNA from the frozen samples of glioblastoma stored in liquid nitrogen. We used NucleoSpin Tissue for DNA isolation. After the DNA was isolated, doublestranded DNA concentrations were measured for bisulfite conversion. We mixed the isolated DNA with pure water, and adjusted it to $5 \mu \mathrm{g} / \mathrm{ml}$. Bisulfite conversion was performed with the EZ DNA Methylation-Gold kit. During the bisulfite treatment, unmethylated cytosine is converted to uracil while methylated cytosine remains unchanged. 
Table 2: Patients characteristics

\begin{tabular}{|c|c|}
\hline Characteristics & $N(\%)$ \\
\hline \multicolumn{2}{|l|}{ Sex } \\
\hline Male & $43(51 \%)$ \\
\hline Female & $41(49 \%)$ \\
\hline \multicolumn{2}{|l|}{ Age } \\
\hline$<60$ & $36(43 \%)$ \\
\hline $60 \leq$ & $48(57 \%)$ \\
\hline \multicolumn{2}{|c|}{ Karnofsky Performance Status } \\
\hline $70 \leq$ & $37(44 \%)$ \\
\hline$<70$ & $47(56 \%)$ \\
\hline \multicolumn{2}{|l|}{ Surgery } \\
\hline Total resection & $36(43 \%)$ \\
\hline Non-total resection & $48(57 \%)$ \\
\hline \multicolumn{2}{|c|}{ MGMT immunohistochemistry } \\
\hline Negative & $20(27 \%)$ \\
\hline Positive & $53(73 \%)$ \\
\hline \multicolumn{2}{|l|}{ IDH1 gene status } \\
\hline Wild-type & $72(94 \%)$ \\
\hline Mutant & $5(6 \%)$ \\
\hline
\end{tabular}

\section{Real time methylation-specific polymerase chain reaction (Real time MSP)}

Brilliant II SYBR Green qPCR Master Mix and two types of primers were used for MSP. Primers were designed for the methylation-favorite site of the MGMT promoter sequences. One type of primer is specific to fully methylated sequences, and recognizes unconverted cytosine during bisulfite treatment, whereas the other type of primer is for fully unmethylated sequences, binding to uracil which is changed from cytosine. The primer sequences are as follows [33]: mMGMT forward 5'-TTTCGACGTTCGTAGGTTTTCGC-3', mMGMT reverse 5'-GCACTCTTCCGAAAACGAAACG-3', uMGMT forward 5'-TTTGTGTTTTGATGTTTGTAG GTTTTTGT-3', and uMGMT reverse 5'-AACTCCACA CTCTTCCAAAAACAAAACA-3'. Real-time PCR was performed at $95^{\circ} \mathrm{C}$ for $15 \mathrm{~min}$, then 38 cycles of $95^{\circ} \mathrm{C}$ for $50 \mathrm{~s}, 59^{\circ} \mathrm{C}$ for $50 \mathrm{~s}$ and $72^{\circ} \mathrm{C}$ for $50 \mathrm{~s}$, followed by a final step at $72^{\circ} \mathrm{C}$ for $10 \mathrm{~min}$. The PCR mixture contains bisulfite-converted DNA, $4 \times$ SYBR Green PCR Master Mix, and each forward and reverse primer. All of the procedures were done in duplicate to confirm repeatability and they were averaged following analysis. A feature of real-time MSP is that we can get two important pieces of data: a dissociation curve and an amplification curve. The dissociation curve shows the temperature at which the DNA undergo a change of state from double strands to a single strand, so one can see if the targeting site of the
MGMT promoter gene is amplified. On the other hand, from the amplification curve, we can observe how much DNA is being amplified over time.

\section{Gel electrophoresis of MSP products}

The real-time MSP products were evaluated using standard 3\% agarose gel-electrophoresis stained with ethidium bromide and they were visualized under ultraviolet illumination to be compared with the real-time MSP results. The bands were present on the gel at 93 bp and 81 bp for unmethylated and methylated MGMT promoter sequence, respectively.

\section{Immunohistochemistry for MGMT protein and IDH1 mutation}

Formalin-fixed paraffin-embedded tissue sections were deparaffinized inxylene on microscopic slides. Antigen retrieval was performed by microwaving the sections in $10 \mathrm{mM}$ citric acid buffer ( $\mathrm{pH}$ 7.2). The primary antibodies used in this study were: anti-human IDH1-R132H monoclonal antibody (1:100, IBL Co., Ltd, Gumma, Japan) and anti-MGMT monoclonal antibody MT3.1 (1:200, Chemicon, Inc., Temecula, CA). The samples were incubated with the primary antibody overnight, followed by incubation with a biotinylated secondary antibody (1:500, Dako, Tokyo, Japan). The bound antibodies were visualized using the avidin biotin 
peroxidase complex method and diaminobenzidine tetrachloride (Santa Cruz Biotechnology, Inc.). To evaluate IDH1 staining, strong cytoplasmic staining in any number of cells was scored as positive. For MGMT scoring, the positive cells in a $200 \times$ field (minimum of 1,000 nuclei) were counted, and the labeling index was expressed as a percentage of the labeled tumor cells. MGMT protein expression $\geq 10 \%$ was considered positive.

\section{Statistical analysis}

Progression-free survival (PFS) was calculated from the date of initial surgery until the first sign of radiological progression, death, or last follow-up. Overall survival (OS) was also calculated from the date of initial surgery until the date of death or last follow-up. Using StatView software (SAS Institute Inc., Cary, NC), the Kaplan-Meier method was used to estimate the survival rates, and the Cox-Mantel log-rank test was applied to compare the survival differences among the patients. The other potential prognostic variables were age, extent of surgery, Karnofsky performance status score, and MGMT protein expression. Multivariate analysis was performed with commercially available software using the Cox proportional hazards regression model (SPSS, Inc., Chicago, IL).

\section{CONFLICTS OF INTEREST} work.

The authors report no conflicts of interest for this

\section{REFERENCES}

1. Zhang J, Stevens MF, Bradshaw TD. Temozolomide: mechanisms of action, repair and resistance. Curr Mol Pharmacol. 2012; 5:102-114.

2. Hegi ME, Diserens AC, Gorlia T, Hamou MF, de Tribolet N, Wellwe M, Kros JM, Hainfellner JA, Mason W, Mariani L, Bromberg JE, Hau P, Mirimanoff RO, et al. MGMT gene silencing and benefit from temozolomide in glioblastoma. N Engl J Med. 2005; 352:997-1003.

3. Esteller M, Garcia-Foncillas J, Andion E, Goodman SN, Hidalgo OF, Vanaclocha V, Baylin SB, Herman JG. Inactivation of the DNA-Repair Gene MGMT and the Clinical Response of Gliomas to Alkylating Agents. N Engl J Med. 2000; 343:1350-1354.

4. Dunn J, Baborie A, Alam F, Joyce K, Moxham M, Sibson R, Crooks D, Husband D, Shenoy A, Brodbelt A, Wong H, Liloglou T, Haylock B, et al. Extent of MGMT promoter methylation correlates with outcome in glioblastomas given temozolomide and radiotherapy. Br J Cancer. 2009; 101:124-131.

5. Rivera AL, Pelloski CE, Gilbert MR, Colman H, De La Cruz C, Sulman EP, Bekele BN, Aldape KD. MGMT promoter methylation is predictive of response to radiotherapy and prognostic in the absence of adjuvant alkylating chemotherapy for glioblastoma. Neuro Oncol. 2010; 12:116-121.

6. Weller M, Stupp R, Reifenberger G, Brandes AA, van den Bent MJ, Wick W, Hegi ME. MGMT promoter methylation in malignant gliomas: ready for personalized medicine? Nat Rev Neurol. 2010; 6:39-51.

7. Yoo B, Ifediba MA, Ghosh S, Medarova Z, Moore A. Combination treatment with theranostic nanoparticles for glioblastoma sensitization to TMZ. Mol Imaging Biol. 2014; 16:680-689.

8. Gibori H, Eliyahu S, Krivitsky A, Ben-Shushan D, Epshtein Y, Tiram G, Blau R, Ofek P, Lee JS, Ruppin E, Landsman L, Barshack I, Satchi-Fainaro R, et al. Amphiphilicnanocarrier-induced modulation of PLK1 and miR-34a leads to improved therapeutic response in pancreatic cancer. Nat Commun. 2018; 9:16.

9. Christians A, Hartmann C, Benner A, Meyer J, von Deimling A, Weller M, Wick W, Weiler M. Prognostic value of three different methods of MGMT promoter methylation analysis in a prospective trial on newly diagnosed glioblastoma. PLoS One. 2012; 7:e33449.

10. Mikeska T, Bock C, El-Maarri O, Hübner A, Ehrentraut D, Schramm J, Felsberg J, Kahl P, Büttner R, Pietsch T, Waha A. Optimization of quantitative MGMT promoter methylation analysis using pyrosequencing and combined bisulfite restriction analysis. J Mol Diagn. 2007; 9:368-381.

11. Hsu CY, Ho HL, Lin SC, Chen MH, Hsu SP, Yen YS, Guo WY, Ho DM. Comparative Assessment of 4 Methods to Analyze MGMT Status in a Series of 121 Glioblastoma Patients. Appl Immunohistochem Mol Morphol. 2017; 25:497-504.

12. Quillien V, Lavenu A, Karayan-Tapon L, Carpentier C, Labussière $\mathrm{M}$, Lesimple $\mathrm{T}$, Chinot $\mathrm{O}$, Wager $\mathrm{M}$, Honnorat $\mathrm{J}$, Saikali S, Fina F, Sanson M, Figarella-Branger D. Comparative assessment of 5 methods (methylation-specific polymerase chain reaction, methylight, pyrosequencing, methylation-sensitive high-resolution melting, and immunohistochemistry) to analyze O6-methylguanine-DNA- methyltranferase in a series of 100 glioblastoma patients. Cancer. 2012; 118:4201-4211.

13. Karayan-Tapon L, Quillien V, Guilhot J, Wager M, Fromont G, Saikali S, Etcheverry A, Hamlat A, Loussouarn D, Campion L, Campone M, Vallette FM, Gratas-Rabbia-Ré C. Prognostic value of O6-methylguanineDNA methyltransferase status in glioblastoma patients, assessed by five different methods. J Neurooncol. 2010; 97:311-322.

14. Bady P, Sciuscio D, Diserens AC, Bloch J, van den Bent MJ, Marosi C, Dietrich PY, Weller M, Mariani L, Heppner FL, Mcdonald DR, Lacombe D, Stupp R, et al. MGMT methylation analysis of glioblastoma on the infinium methylation beadchip identifies two distinct $\mathrm{CpG}$ regions associated with gene silencing and outcome, yielding a prediction 
model for comparisons across datasets, tumor grades and CIMP-status. Acta Neuropathol. 2012; 124:547-560.

15. Vlassenbroeck I, Califice S, Diserens AC, Migliavacca E, Straub J, Di Stefano I, Moreau F, Hamou MF, Renard I, Delorenzi M, Flamion B, DiGuiseppi J, Bierau K, et al. Validation of real-time methylation-specific PCR to determine O6-methylguanine-DNA methyltransferase gene promoter methylation in glioma. J Mol Diagn. 2008; 10:332-337.

16. Ogino S, Kawasaki T, Brahmandam M, Cantor M, Kirkner GJ, Spiegelman D, Mak rigiorgos GM, Weisenberger DJ, Laird PW, Loda M, Fuchs CS. Precision and performance characteristics of bisulfite conversion and real-time PCR (methylight) for quantitative DNA methylation analysis. J Mol Diagn. 2006; 8:209-217.

17. Hattermann K, Mehdorn HM, Mentlein R, Schultka S, Held-Feindt J. A methylation-specific and SYBR-greenbased quantitative polymerase chain reaction technique for O6-methylguanine DNA methyltransferase promoter methylation analysis. Anal Biochem. 2008; 377:62-71.

18. Brell M, Tortosa A, Verger E, Gil JM, Viñolas N, Villá S, Acebes JJ, Caral L, Pujol T, Ferrer I, Ribalta T, Graus F. Prognostic significance of O6-methylguanine-DNA methyltransferase determined by promoter hypermethylation and immunohistochemical expression in anaplastic gliomas. Clin Cancer Res. 2005; 15:5167-5174.

19. Blanc JL, Wager M, Guilhot J, Kusy S, Bataille B, Chantereau T, Lapierre F, Larsen CJ, Karayan-Tapon L. Correlation of clinical features and methylation status of MGMT gene promoter in glioblastoma. J Neurooncol. 2004; 68:275-283.

20. Felsberg J, Rapp M, Loeser S, Fimmers R, Stummer W, Goeppert M, Steiger HJ, Friedensdorf B, Reifenberger G, Sabel MC. Prognostic significance of molecular markers and extent of resection in primary glioblastoma patients. Clin Cancer Res. 2009; 15:6683-6693.

21. Hegi ME, Diserens AC, Godard S, Dietrich PY, Regli L, Ostermann S, Otten P, Van Melle G, de Tribolet N, Stupp R. Clinical trial substantiates the predictive value of O-6methylguanine-DNA methyltransferase promoter methylation in glioblastoma patients treated with temozolomide. Clin Cancer Res. 2004; 10:1871-1874.

22. Cao VT, Jung TY, Jung S, Jin SG, Moon KS, Kim IY, Kang SS, Park CS, Lee KH, Chae HJ. The correlation and prognostic significance of MGMT promoter methylation and MGMT protein in glioblastomas. Neurosurgery. 2009; 65:866-875.

23. Lalezari S, Chou AP, Tran A, Solis OE, Khanlou N, Chen W, Li S, Carrillo JA, Chowdhury R, Selfridge J, Sanchez DE, Wilson RW, Zurayk M, et al. Combined analysis of O6-methylguanine-DNA methyltransferase protein expression and promoter methylation provides optimized prognostication of glioblastoma outcome. Neuro Oncol. 2013; 15:370-381.

24. Hsu CY, Ho HL, Lin SC, Chang-Chien YC, Chen MH, Hsu SP, Yen YS, Guo WY, Ho DM. Prognosis of glioblastoma with faint MGMT methylation-specific PCR product. J Neurooncol. 2015; 122:179-188.

25. Brell M, Ibáñez J, Tortosa A. O6-Methylguanine-DNA methyltransferase protein expression by immunohistochemistry in brain and non-brain systemic tumours: systematic review and meta-analysis of correlation with methylation-specific polymerase chain reaction. BMC Cancer. 2011; 11:35.

26. Everhard S, Tost J, El Abdalaoui H, Crinière E, Busato F, Marie Y, Gut IG, Sanson M, Mokhtari K, Laigle-Donadey F, Hoang-Xuan K, Delattre JY, Thillet J. Identification of regions correlating MGMT promoter methylation and gene expression in glioblastomas. Neuro Oncol. 2009; 11:348-356.

27. Brandes AA, Franceschi E, Tosoni A, Blatt V, Pession A, Tallini G, Bertorelle R, Bartolini S, Calbucci F, Andreoli A, Frezza G, Leonardi M, Spagnolli F, et al. MGMT Promoter Methylation Status Can Predict the Incidence and Outcome of Pseudoprogression After Concomitant Radiochemotherapy in Newly Diagnosed Glioblastoma Patients. J Clin Oncol. 2008; 26:2192-2197.

28. Zhang K, Wang XQ, Zhou B, Zhang L. The prognostic value of MGMT promoter methylation in Glioblastoma multiforme: a meta-analysis. Fam Cancer. 2013; 12:449-458.

29. Zawlik I, Vaccarella S, Kita D, Mittelbronn M, Franceschi S, Ohgaki H. Promoter methylation and polymorphisms of the MGMT gene in glioblastomas: a population-based study. Neuroepidemiology. 2009; 32:1-9.

30. Hamilton MG, Roldán G, Magliocco A, McIntyre JB, Parney I, Easaw JC. Determination of the methylation status of MGMT in different regions within glioblastoma multiforme. J Neurooncol. 2011; 102:255-260.

31. Parker NR, Hudson AL, Khong P, Parkinson JF, Dwight T, Ikin RJ, Zhu Y, Cheng ZJ, Vafaee F, Chen J, Wheeler HR, Howell VM. Intratumoral heterogeneity identified at the epigenetic, genetic and transcriptional level in glioblastoma. Sci Rep. 2016; 4:22477.

32. Håvik AB, Brandal $\mathrm{P}$, Honne $\mathrm{H}$, Dahlback HS, Scheie D, Hektoen M, Meling TR, Helseth E, Heim S, Lothe RA, Lind GE. MGMT promoter methylation in gliomas-assessment by pyrosequencing and quantitative methylation-specific PCR. J Transl Med. 2012; 6:10-36.

33. Uno M, Oba-Shinjo SM, Camargo AA, Moura RP, Aguiar PH, Cabrera HN, Begnami M, Rosemberg S, Teixeira MJ, Marie SK. Correlation of MGMT promoter methylation status with gene and protein expression levels in glioblastoma. Clinics (Sao Paulo). 2011; 66:1747-1755. 